\title{
LÍNGUA, PRA QUE TE QUERO? : PRINCÍPIOS SOCIOLINGUÍSTICOS APLICADOS AO ENSINO DE LÍNGUA PORTUGUESA
}

\author{
Cristiano Sandim Paschoal ${ }^{1}$
}

\begin{abstract}
Resumo: Este artigo busca mostrar uma possibilidade de aplicação didática dos princípios sociolinguísticos no ensino da educação básica. Ancorando-se na teoria variacionista fomentada por William Labov, esboça-se um minidicionário produzido por uma turma de nono ano, de uma escola do interior do Rio Grande do Sul, contendo várias expressóes peculiares utilizadas no cotidiano dos moradores da região. Concluiu-se, após a aplicação desta metodologia de ensino, que a oralidade deve ser valorizada em sala de aula e, acima de tudo, que o papel da escola, em relação ao ensino de língua portuguesa, é mostrar que a língua funciona como uma espécie de roupagem, podendo o aluno vestir-se a depender do contexto de uso.
\end{abstract}

Palavras-chave: Sociolinguística. Contexto de uso. Variação. Ensino de Língua Portuguesa.

\section{LANGUAGE, WHAT DO I WANT YOU FOR? : SOCIO- LINGUISTIC PRINCIPLES APPLIED TO PORTUGUESE LANGUAGE TEACHING}

\begin{abstract}
This article aims to show a possibility of didactic application of sociolinguistic principles in basic education teaching. Grounded on the variationist theory promoted by William Labov, a mini-dictionary is designed and produced by ninth grade students from a school in the countryside of Rio Grande do Sul, containing a plethora of peculiar expressions used in the daily lives of the inhabitants of the region. It was concluded that, after the application of this teaching methodology, orality should be valued in the classroom and, above all, that the role of the school, in relation to the teaching of the Portuguese language, is to show that the language suits as a sort of outfit, that the students may wear depending on the context of use.
\end{abstract}

Keywords: Sociolinguistics Context of use. Variation. Portuguese language teaching.

1 Graduado em Letras Português, Espanhol e respectivas Literaturas (UNISC). Mestrando em Linguística/Teoria e Usos da linguagem pela Pontifícia Universidade Católica do Rio Grande do Sul, bolsista CAPES/PROEX. Integrante do Grupo Tessitura: Vozes em (Dis)curso (PUCRS/ CNPq). E-mail: cristiano.paschoal@edu.pucrs.br. ORCID: 0000-0002-1638-4120. 


\section{Introduçáo}

O processo de ensino-aprendizagem na Educação tem sido, há um bom tempo, motivo de preocupação para especialistas da área. Tal preocupação engloba fatores de diversas naturezas, desde fundamentos teóricos adotados por professores e pela escola até a prática pedagógica em sala de aula.

Partindo-se do pressuposto de que o principal objetivo da escola é a formação de cidadãos ativos para com as práticas sociais que o mundo exige, incluindo, principalmente, práticas discursivas linguísticas, uma vez que é através da linguagem que nos constituímos, este artigo busca refletir sobre o posicionamento da escola perante o ensino de língua materna, partindo da seguinte afirmativa do linguista Marcos Bagno (2014), em sua obra intitulada Lingua, linguagem, linguísticapondo os pingos nos $i$ :

Muitas e muitas pessoas abandonam os estudos porque ficam traumatizadas ao entrar na escola e, logo em seus primeiros contatos com o mundo escolar, são alvo de discriminação, de deboche, de piada por causa de seu jeito de falar - discriminação praticada não só pelos colegas, mas também por muitas professoras e muitos professores. (BAGNO, 2014, p. 57).

Ancorando-se em concepções da linguagem como sendo um processo interativo que se realiza nas práticas sociais, tendo como arcabouço fundador os estudos da Sociolinguística, o presente trabalho busca esboçar um projeto realizado em uma escola do interior do Rio Grande do Sul, elaborado por um professor de língua portuguesa (autor deste artigo) juntamente com uma turma de nono ano. Como percurso, serão apresentados, inicialmente, os princípios da ciência Sociolinguística; em um segundo, apresenta-se, sumariamente, como a escola trata, de maneira geral, o ensino de língua materna. Após, esboça-se o projeto, que consiste numa compilação de expressões utilizadas no cotidiano pelos moradores da região interiorana em que a escola se encontra. Por fim, fazem-se as considerações finais refletindo sobre o que neste artigo foi esboçado.

\section{Concepçóes preliminares: da estrutura ao social}

Para que se discorra sobre o comportamento da escola diante do ensino da linguagem verbal, necessita-se abordar, preliminarmente, algumas concepções que se fazem subjacentes ao ensino de língua materna, uma vez que "o ponto de vista cria o objeto" (SAUSSURE, 2012, p. 15).

Nesse sentido, em se tratando de linguagem e ensino, a noção aqui adotada para o termo linguagem é, em termos gerais, como sendo um sistema de representação organizado que serve, dentre muitas coisas, principalmente, para seus usuários se integrarem e interagirem socialmente. Tal representação e, pois, interação, ocorrerá por meios gestuais, pictóricos, numéricos, entre outros, ou seja, a dança, as placas de sinais, as placas de trânsito, a arquitetura, por exemplo, são, de fato, linguagens, uma vez que possuem um sistema organizado que representa a realidade para/com o homem. 
Entretanto, visto que o presente estudo visa a abordar como são tratados os aspectos linguísticos na escola, faz-se importante conceituar o objeto de estudo da ciência Linguística que, em 1916, no Curso de Linguística Geral², foi delimitado por Ferdinand de Saussure:

Das incursões que acabamos de fazer nos domínios limítrofes de nossa ciência, se depreende um ensinamento inteiramente negativo, mas tanto mais interessante quanto concorda com a ideia fundamental deste curso: a Linguística tem por único e verdadeiro objeto a língua considerada em si mesma e por si mesma. (SAUSSURE, 2012, p. 271).

Delimitando, então, a língua como objeto de estudo, sendo um sistema da linguagem verbal constituído por signos ${ }^{3}$, o professor genebrino, considerado o pai da Linguística, irá concebê-la como algo social, porém sistemático, uma vez que poderá haver diferentes "falares", porém entendíveis, em uma mesma língua.

Contudo, a partir da segunda metade do século XX, a ciência Linguística passa a não somente analisar os fundamentos criados por Saussure, mas, também, ampliá-los. A língua, por exemplo, vista anteriormente pelo linguista como um sistema estruturado, passa a ser abordada como um sistema vinculado às práticas sociais, sendo, parte desta abordagem, apresentada a seguir.

\section{Língua e variaçáo}

Apesar de Ferdinand de Saussure desenvolver e fundamentar a ciência Linguística, sua visão de língua enquanto estrutura não deu conta da complexidade do campo de estudo da linguagem verbal. Nesse sentido, surge, na metade do século XX, um ramo da Linguística que abordará os fenômenos da língua ligados às práticas sociais: a Sociolinguística.

Iniciada, nos Estados Unidos (1960) sob a coordenação do linguista William Labov $^{4}$, trata-se de uma ciência que tem como principal objeto de estudo a diversidade linguística, em sentido mais amplo. Isto significa que a Sociolinguística analisa os aspectos sociais atrelados à linguagem verbal e vice-versa. Entretanto, faz-se importante observar que isto não significa que Saussure não considerou a língua como sendo um corpo/organismo social, porém o linguista, ao construir seu construto teórico, delimitou seu estudo para a parte estrutural da língua, deixando a fala de fora de suas análises. Em contrapartida, a Sociolinguística tratará também da língua, porém se concentrando em suas manifestações orais:

2 O Curso de Linguística Geral (CLG) não foi escrito por Ferdinand de Saussure. Trata-se de um conjunto de anotações de seus alunos, a partir dos cursos ministrados pelo linguista na Universidade de Genebra, compilado por Charles Bally, Albert Sechehaye e Albert Riedlinger.

3 Para Saussure, o signo linguístico era a união indivisível entre um significante (imagem acústica) e um significado (conceito).

4 Para maiores aprofundamentos epistemológicos sobre a área Sociolinguística, indica-se a leitura da obra Padrões sociolinguísticos (2008). 
A Sociolinguística vai mostrar os problemas de variação linguística e da norma-culta. Se linguisticamente não existe o certo e o errado, mas o diferente, socialmente as coisas não caminham desse modo. A sociedade se apega a fatos linguísticos, que por si são neutros, a fim de usá-los como argumento para seus preconceitos. Por exemplo, falar usando o r caipira não mostra nada de bom ou ruim do ponto de vista da estrutura fonológica da língua. Porém, se alguém falar desse modo no Rio de Janeiro, provavelmente vai será objeto de zombaria ou terá prejuízos sociais, por exemplo, não sendo aceito para um emprego que o obrigue a lidar com o público carioca. O preconceito é social, mas sua manifestação se dá através das atitudes das pessoas diante de fatos linguísticos. (CAGLIARI, 2003, p. 47).

Logo, os estudos sociolinguísticos mostram que não somos unilíngues nem mesmo dentro de nossa própria língua, configurando uma diversidade de grupos sociais e, concomitantemente, linguísticos. A língua, sob esta perspectiva, apresentar-se-á de diversas formas, a depender dos seguintes critérios:

\section{Figura 1 - Esboço dos principais critérios que influenciam na variação linguística}

\begin{tabular}{|c|c|}
\hline $\begin{array}{l}\text { CRITÉRIO } \\
\text { REGIONAL }\end{array}$ & $\begin{array}{l}\text { A variação regional, chamada cientificamente de diatópica, mostra que diferentes } \\
\text { regiões que falam a mesma língua podem apresentá-la de maneiras distintas na } \\
\text { oralidade, seja em relação ao léxico, seja em relação à pronúncia. Um exemplo } \\
\text { exímio disto são as diferentes maneiras que a letra r, por exemplo, é pronunciada } \\
\text { no Brasil. }\end{array}$ \\
\hline $\begin{array}{l}\text { CRITÉRIO } \\
\text { HISTÓRICO }\end{array}$ & $\begin{array}{l}\text { A variação histórica diz respeito às transformações, também chamadas de } \\
\text { mudança linguística, que os aspectos formais, semânticos e sonoros da língua } \\
\text { sofrem. }\end{array}$ \\
\hline $\begin{array}{l}\text { CRITÉRIO } \\
\text { SOCIAL }\end{array}$ & $\begin{array}{l}\text { O fenômeno chamado de variação social mostra os diferentes "falares" de uma } \\
\text { mesma língua, a depender das diferenças socioeconômicas de seus falantes, suas } \\
\text { idades, sexo, escolaridade, entre outras; consiste no uso que se faz da língua em } \\
\text { função da situação em que o falante vive. }\end{array}$ \\
\hline $\begin{array}{l}\text { CRITÉRIO } \\
\text { CONTEXTUAL }\end{array}$ & $\begin{array}{l}\text { Denominada variação diafásica, refere-se na situação discursiva em que os } \\
\text { interlocutores estão envolvidos. Por exemplo, um falante utilizará uma linguagem } \\
\text { em uma situação de entrevista de emprego diferente da linguagem utilizada com } \\
\text { seus pais, de nível familiar, menos formal. Também, há nesse critério uma variação, } \\
\text { inclusive na escrita, uma vez que um texto acadêmico será escrito com um grau } \\
\text { de formalidade muito maior que em uma conversa de aplicativo } W \text { hats } A p p \text {, por } \\
\text { exemplo. Salienta-se, ainda, que essa adequação linguística recebe uma designação } \\
\text { especial na Sociolinguística, chamada registro. }\end{array}$ \\
\hline $\begin{array}{l}\text { CRITÉRIO } \\
\text { PADRÃO: }\end{array}$ & $\begin{array}{l}\text { Trata-se de uma variação cujo nome é designado de padrão por uma questão } \\
\text { puramente histórico-cultural. Tradicionalmente, durante a história do ensino da } \\
\text { linguagem verbal, os principais manuais de gramática idealizavam uma língua- } \\
\text { padrão baseada em clássicos literários. Entretanto, do ponto de vista linguístico, } \\
\text { a língua portuguesa, como qualquer língua, tem o certo e o errado } \\
\text { somente em relação à sua estrutura. Com relação a seu uso pelas } \\
\text { comunidades falantes, não existe o certo e o errado linguisticamente, mas } \\
\text { o diferente. Por exemplo, um falante do português dizer Carta eu longa } \\
\text { escrevi uma em vez de Eu escrevi uma longa carta é um erro, porque } \\
\text { o sistema da língua não permite que as palavras fiquem nessa ordem. Se } \\
\text { em vez de dizer cavalo alguém diz panela é um erro linguístico em relação } \\
\text { ao português. Esses são erros porque vão contra o sistema, a estrutura da } \\
\text { língua. (CAGLIARI, 2003, p. 35, grifos nossos). }\end{array}$ \\
\hline
\end{tabular}

Fonte: Elaborado pelo autor a partir das leituras feitas dos textos de Luiz Carlos Cagliari (2003) e Ronald Beline (2015). 
Observa-se, também, que, além da variação linguística ocorrer em consequência dos critérios acima citados, ela pode chegar a nível individual, porém

embora o indivíduo possa utilizar variantes, é no contato linguístico com outros falantes de sua comunidade que ele vai encontrar os limites para a sua variação individual. Como o indivíduo vive inserido numa comunidade, deverá haver semelhanças entre a língua que ele fala e a que os outros membros da comunidade falam. (BELINE, 2015, p. 128).

\section{Língua e escola}

Partindo-se do pressuposto de que a escola é um dos maiores agentes de transformação social, pergunta-se: como e o que a escola está ensinando em relação à disciplina de língua portuguesa? A metodologia adotada na escola está, de fato, obtendo bons resultados?

Este artigo ocupou-se da investigação ligada ao ensino público, partindo de uma alarmante constatação divulgada por uma plataforma digital, criada pelo Inep (Instituto Nacional de Estudos e Pesquisa Educacionais).

Segundo dados coletados provenientes da Prova Brasil de 2013 na plataforma do instituto (NOTA, 2013), que organiza diferentes mecanismos e tipos de avaliações ${ }^{5}$ cujo principal objetivo é a averiguação do processo de ensinoaprendizagem em diferentes níveis do ensino, 22,98 \% dos alunos do nono ano, de uma escola de Ensino Fundamental, apresentaram nível de proficiência em Língua Portuguesa abaixo de 1, dentre oito níveis elaborados pela comissão organizadora da prova.

Nesse sentido, considerando que tais avaliações se pautam em competências discursivas da Língua Portuguesa, pode-se concluir que, mesmo com os avanços científicos dos estudos relacionados à linguagem verbal, a escola (ou boa parte dela) ainda continua restrita ao ensino de gramática normativa. Mas, afinal, o que é gramática normativa?

A gramática normativa é, basicamente, um conjunto de regras prescritivas do funcionamento da língua, estabelecendo usos da língua como sendo "corretos" em detrimento a outros "incorretos". Carecendo de uma perspectiva empírica dos fatos relacionados aos diferentes usos da língua, essa concepção de linguagem se baseia, unicamente, na variante padrão da língua, tendo-a como modelo "exemplar" de um idioma. Portanto, isso significa dizer que, de maneira geral,

5 Dentre as avaliações que se encontram sob coordenação do instituto INEP, encontram-se: SAEB (Sistema de Avaliação da Educação Básica) cujas implementações de avaliações estão a ANEB (Avaliação Nacional de Educação Básica), a Prova Brasil/ANRESC (Avaliação Nacional de Rendimento Escolar) e a ANA (Avaliação Nacional da Alfabetização). Também, encontramse, na gama destas averiguações, o PISA (Programa Internacional de Avaliação de Estudantes), o ENEM (Exame Nacional do Ensino Médio) e o ENADE (Exame Nacional de Desempenho de Estudantes). 
o aluno passa anos e anos, diariamente, em aulas de português, e o que aprende? Sempre as mesmas coisas: o que significa a palavra...telúrico? como se escrevem as palavras...exceção, extenso e estender? qual o plural de... cidadão? a que categorias gramaticais pertencem as palavras...mal e mau? o que é substantivo concreto e abstrato? qual é o coletivo de lobo? qual é o sujeito das orações [...]. (CAGLIARI, 2003, p. 24).

Resumindo, o ensino de língua portuguesa, pautado numa perspectiva normativa, reduz a complexidade da linguagem verbal à taxionomia de categorias gramaticais, esquecendo que o sujeito aluno já possui internalizada a prática de sua língua materna, vendo-o como tábula rasa, linguisticamente. Esquece-se, ainda, de ensinar os reais objetivos do ensino relacionado à linguagem que são os aspectos discursivos relacionados ao seu funcionamento interno e, também, externo, mostrando ao aluno a importância real de estudar uma língua.

Contudo, esclarece-se que o que está sendo defendido neste artigo não é a retirada total do ensino de gramática na escola, mas, sim, preconiza-se, acima de tudo, uma mudança em sua abordagem, pois:

[...] Uma receita de bolo não é um bolo [...]. Também a gramática não é a língua. A língua é um enorme iceberg flutuando no mar do tempo, e a gramática normativa é a tentativa de descrever apenas uma parcela mais visível dele, a chamada norma culta. Essa descrição, é claro, tem seu valor e seus méritos, mas é parcial (no sentido literal e figurado do termo) e não pode ser autoritariamente aplicada a todo resto da língua [...]. (BAGNO, 2007, p. 9).

Nesse sentido, sugere-se um olhar para a educação linguística que perceba as diferentes maneiras que a língua pode ser configurada no uso, a depender do propósito estabelecido pelo falante, em uma situação discursiva. A língua, quando apresentada sob os preceitos gramaticais, insere-se em uma determinada situação e implica algum tipo de funcionalidade. Todavia, nem sempre o seu uso a rigor é bem vindo, pois dependendo da esfera de atividade em que se encontra inserida pode não atingir os efeitos de sentidos desejados ao qual um contexto situacional se propõe.

\section{O minidicionário}

Antes de o minidicionário ser construído, o professor, durante cinco encontros semanais, abordou com os alunos todos os princípios, anteriormente apresentados, a saber: linguagem verbal, língua, variação linguística (regional, histórica, social e norma padrão), situação de uso e gíria. No entanto, fez-se uma abordagem mais didática, ou seja, menos técnica, trazendo os conceitos através de textos com gírias, vídeos retirados do Youtube que demonstravam e retratavam os diferentes falares brasileiros, uma música contendo um desvio gramatical, enfim, evidenciou-se que, sob o viés sociolinguístico, a língua se configura conforme o contexto em que se encontra inserida.

Em um primeiro momento, foi explorada uma tirinha contendo uma situação de uso que demonstra um distanciamento semântico que muitas vezes ocorre 
entre diferentes gerações quanto ao uso de uma palavra. Segue o gênero discursivo utilizado:

Figura 2 - Tirinha do Menino Maluquinho
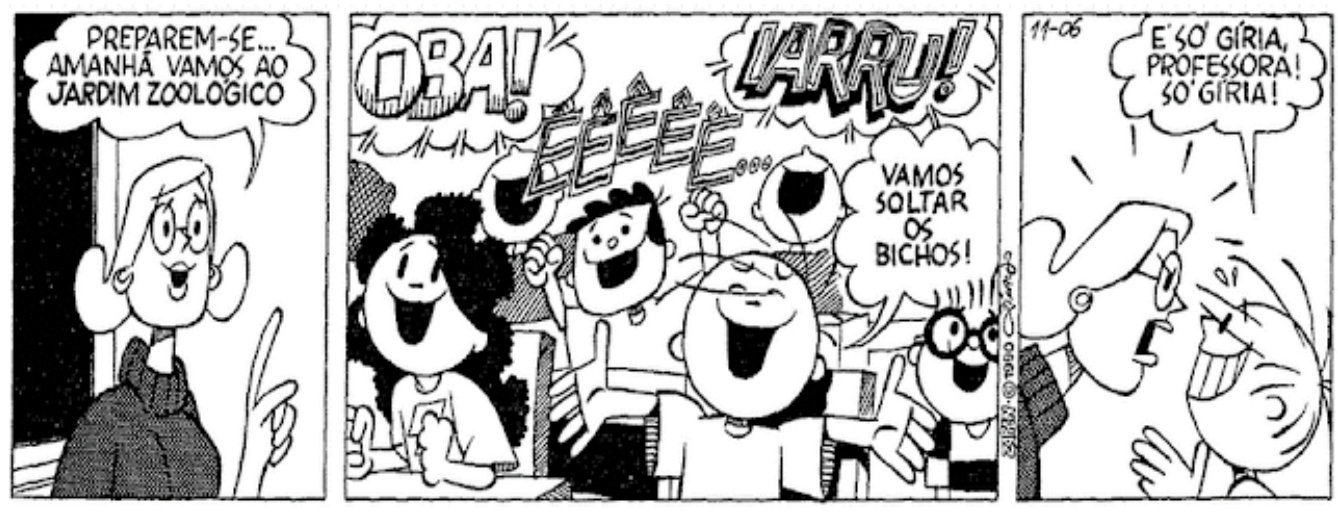

Fonte: (FORMAÇÃO, 2018, [s/p]).

A partir da análise conjunta com os estudantes, propôs-se um diálogo sobre situações das quais eles já haviam presenciado em que seus próprios usos linguísticos tivessem causado estranhamento e valoração significativa contrária com pessoas de faixa etária maior como, por exemplo, familiares. Nesse momento, foram relatadas diversas histórias que envolviam, geralmente, desentendimento semântico por parte de familiares devido ao uso de gírias pelos jovens estudantes. Um aluno, por exemplo, narrou a história de o fato de sua mãe não entender o motivo pelo qual ele chamava seu melhor amigo de brou. Outro, por sua vez, contou algo engraçado, pois chamou o celular de sua avó de cebola e ela havia compreendido que ele estava desejando comer a planta hortense. Dentre as muitas narrativas, destacou-se, também, a de um menino que se dirigiu à diretoria escolar utilizando o termo cara, o que the rendeu uma reunião com os pais e a coordenação escolar.

Em relação ao desvio gramatical, utilizou-se o gênero discursivo musical para esboçar tal configuração linguística:

Beija Eu

Arnaldo Antunes

Beija eu,

Beija eu,

Deixa que eu seja eu.

E aceita

o que seja seu.

Então deita e aceita eu.

Molha eu,

Seca eu,

Deixa que eu seja o céu. 


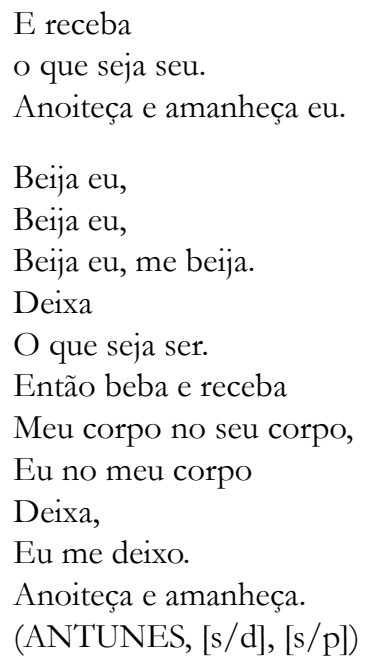

Ao analisar-se a música Beija eu, composta por Arnaldo Antunes e geralmente interpretada pela cantora brasileira Marisa Monte, foram evocados, juntamente com o nono ano, as compreensões de sentidos possíveis que podiam emergir do texto musical. No entanto, o que se pretendeu destacar foi a questão da adequação linguística.

A Gramática Normativa prescreve em seus princípios que, tanto no uso oral quanto no escrito, os pronomes pessoais de caso reto (eu, tu, ele, ela, nós, vós eles e elas) exercem a função sintática de sujeito ou predicativo do sujeito e, por isso, não podem ser usados como complementos verbais. Nesse sentido, quando o autor da música acima esboçada utiliza a primeira pessoa do singular (eu) após verbos como molhar, secar, ser, entre outros, estaria cometendo um "erro". Não obstante, durante essa reflexão, esclareceu-se aos alunos que supostos desvios linguísticos que seus usuários da língua podem cometer, muitas vezes, são propositais. No universo artístico-literário, por exemplo, certos desvios são cometidos, textual e oralmente, para fins de efeitos de sentido. No caso da música em análise, o autor provavelmente tinha o intento de atingir seu interlocutor emocionalmente, aproximando o sentido da música ao seu universo linguístico e, consequentemente, a sua realidade concreta da vida. Contudo, destacou-se, também, a necessidade de se observar os graus de formalidade em que os textos escritos e orais se atrelam, pois, muitas vezes, o uso da norma padrão se faz imprescindível. Quanto a isso, atentou-se para o fato de que, em algumas esferas de atividade, como por exemplo, a esfera jurídica, o uso normativo da língua impera não apenas para padronizar aquilo que está sendo, textualmente, legalizado, mas, também, para evitar ao máximo, mesmo que não se consiga, pluralidade de interpretações, ambiguidades e outros mecanismos que sugerem a não compreensão. Atrelado a isso, o uso da norma padrão permite que um texto, por exemplo, escrito no interior do Rio Grande do Sul se torne inteligível em qualquer região do estado da Bahia, de São Paulo, Minas Gerais e assim por diante. 
Por fim, antes do projeto principal que corresponde ao minidicionário, foi exposto à turma um vídeo retirado da ferramenta digital Youtube, cuja imagem se faz configurada a seguir:

Figura 3 - Vídeo assistido em aula

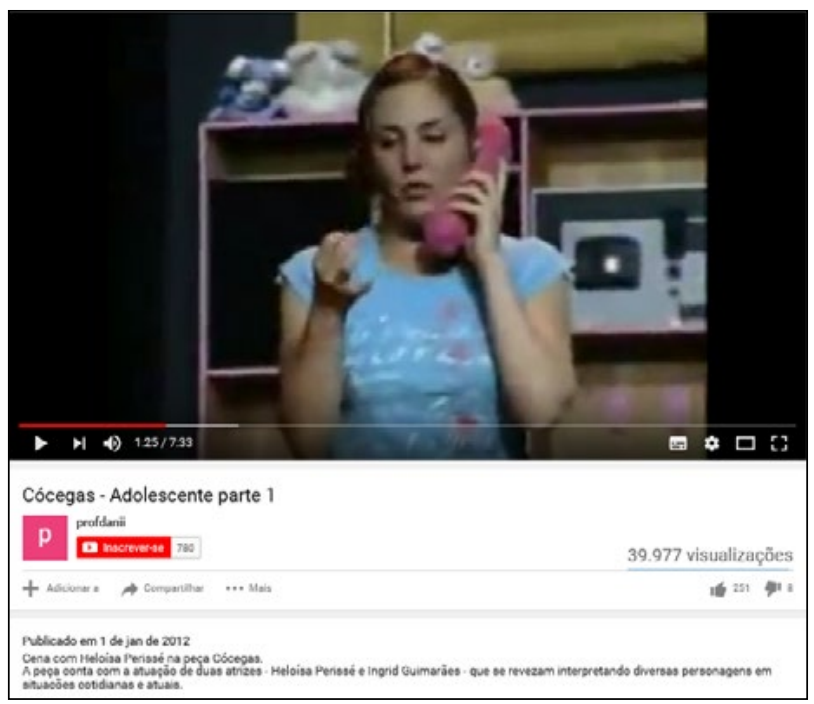

Fonte: Print do vídeo “Cócegas -Adolescente parte 1” (CÓCEGAS, 2012, [s/p]).

A imagem antes esboçada representa uma das esquetes ${ }^{6}$ da peça teatral Cócegas, escrita e interpretada no ano de 2001 pelas atrizes Ingrid Guimarães e Heloísa Périssé. Intitulado como Adolescente, o quadro cênico acima retrata a história de uma menina chamada Tati que, além de apresentar as características conflituosas da adolescência, utiliza de um repertório linguístico permeado por várias gírias: caraca, veio, tipo assim, meo, tudo lega, etc.

Nesse percurso, observou-se a alegria dos estudantes ao saberem que a variação utilizada por eles não era "errada", mas, simplesmente, uma forma de uso contextualizada. Entretanto, ao mesmo tempo, sempre lhes era lembrado a necessidade de se apropriarem da norma padrão por motivos de promoção social e garantia de futuro, uma vez que vivemos em um país cujo preconceito linguístico impera e o seu domínio possibilita ao falante perpassar pelas diversas esferas de atividade que se fomentam no universo social.

Para realização do minidicionário, além das gírias utilizadas pelos próprios alunos, foram feitas entrevistas informais com os moradores da região, muitos deles com idades mais avançadas, intuindo, assim, resgatar expressões históricas que foram e ainda são utilizadas na região. Ao todo, foram compiladas 47 expressões. Seguem as expressões com seus significados e/ou sentido no contexto de uso:

6 No universo teatral chama-se de esquete um quadro cênico de curta duração. 
Figura 4 - Conjunto de expressões compiladas pelos alunos

\begin{tabular}{|c|c|}
\hline Expressão & Significado \\
\hline Aprochegar & Aproximar-se. \\
\hline Arredar-se & Afastar-se de alguém. \\
\hline Arriar & Fazer algo engraçado. \\
\hline Baaaa & Que parece engraçado, mas não têm graça nenhuma. Tom irônico. \\
\hline Bagual & Bom. \\
\hline Baita & Algo grande. \\
\hline Baita fado & Música boa. \\
\hline Baita gado & Mulher gorda. \\
\hline Beleléu & Fim do mundo. \\
\hline Buchechuda & Grávida. \\
\hline Buenas & $\begin{array}{l}\text { Estar bem. Geralmente quando alguém pergunta como a pessoa está e a } \\
\text { outra responde "buenas". }\end{array}$ \\
\hline Bugado & Quebrado, estragado. \\
\hline Bruxo & Irmão. \\
\hline Cabuloso & Algo ou alguém chato. \\
\hline $\begin{array}{l}\text { Cair os butiás do } \\
\text { bolso }\end{array}$ & Ficar surpreso ou espantado. \\
\hline $\begin{array}{l}\text { Caixão e vela preta } \\
\text { pra ele(a): }\end{array}$ & Alguém que está muito doente. \\
\hline Celu & Celular. \\
\hline Cebola & Celular antigo e de tamanho grande. \\
\hline Chips & Qualquer tipo de biscoito salgado. \\
\hline Chirú & Menino, rapaz, guri. \\
\hline Cumpadi/cumadi & Compadre/comadre. \\
\hline Cusco & Cachorro. \\
\hline Deitar o cabelo & Fugir. \\
\hline Diabão & Pessoa que é boa em algo. \\
\hline Distorcida & Pessoa ágil e competente. \\
\hline Embutado & Enrascado, em apuros. \\
\hline $\begin{array}{l}\text { Frio de renguiar } \\
\text { cusco }\end{array}$ & A temperatura está extremamente fria. \\
\hline Gaia & Chifre. Quando um homem foi traído, ele ganhou "gaia". \\
\hline Gatão & Homem feio. \\
\hline Guaipeca & Cachorro magro. \\
\hline Lagartear & Descansar. \\
\hline Magrela & Bicicleta. \\
\hline Meu fã & $\begin{array}{l}\text { Pessoa que curte muitas fotos suas no Facebook ou um colega de aula que } \\
\text { o imita muito. }\end{array}$ \\
\hline Mete o pé & Saia já daqui. \\
\hline Morô? & Entendeu? \\
\hline Nunca nem vi & Não sei de nada. Também pode significar qualquer tipo de negação. \\
\hline Patelta & Pessoa devagar. \\
\hline Pela saco & Pessoa inoportuna. \\
\hline Pentear & Transar. \\
\hline Piçasso & Fiasco. Quando algo não dará certo, será um piçasso. \\
\hline Que zica & Que azar. \\
\hline
\end{tabular}




\begin{tabular}{|l|l|}
\hline \multicolumn{1}{|c|}{ Expressão } & \multicolumn{1}{c|}{ Significado } \\
\hline Responsa & Pessoa confiável. \\
\hline Saci fufu & Deu tudo errado, se deu mal. Azarou-se. \\
\hline Sequela & Pessoa que tem dificuldade para pensar. \\
\hline $\begin{array}{l}\text { Vamo tocá que a preta } \\
\text { pega nóis }\end{array}$ & Vamos trabalhar, pois a noite está chegando. \\
\hline Véi & $\begin{array}{l}\text { Cumprimento para colegas ou reclamação de que tudo deu errado, a } \\
\text { depender do contexto e entonação da voz. }\end{array}$ \\
\hline Xanha & Coceira no corpo. \\
\hline Zambeta & Pessoa que possui pernas tortas. \\
\hline
\end{tabular}

Fonte: Planilha elaborada a partir das entrevistas realizadas pelos alunos.

Depreende-se, a partir das expressões compiladas, que o minidicionário obtido apresenta uma linguagem bastante peculiar, justamente por ser atravessado por uma diversidade de fatores culturais e linguístico-discursivos. Sob o prisma cultural, percebem-se heranças linguísticas de influência gaúcha fronteiriça (chirú), portuguesa (baita fado), de ordem religiosa (caixão e vela preta), dentre outras. Quanto ao aspecto discursivo, que se refere a uso, pode-se observar que, embora exista o significado dicionarizado no conjunto lexical de uma língua, é no uso que as palavras adquirem sentido. No enunciado Vamo tocá que a preta pega nóis, por exemplo, o termo preta significará noite, não tonalidade, indicando um acordo semântico entre os usuários que compartilham um mesmo código linguístico.

\section{Conclusáo: língua, pra que te quero?}

Como dito anteriormente, busca-se, para a melhora do ensino de língua portuguesa, uma diferente abordagem que abarque todas as possíveis manifestações de uso da língua. Para tanto, tarefa que não é fácil, faz-se necessária a implementação de estudos sociolinguísticos no ambiente pedagógico. Considera-se difícil tal mecanismo, primeiro, porque a Linguística não é uma ciência para o ensino, ou seja, suscita-se o deslocamento de parte de seus construtos teóricos, algo que deve ser feito por linguistas. Segundo, é importante um maior investimento, por parte do governo, na formação continuada do professor, que também precisa buscar evolução intelectual. E, por fim, a escola, como um todo, tem a obrigação de se auto perguntar: Língua, pra que te quero?

Levando tal questionamento em consideração, abre-se, dentro do ensino de Língua Portuguesa, um caminho de diferentes possibilidades de pensares sobre as possíveis manifestações existentes da linguagem. A escola fazendo este tipo de questionamento perceberá a língua como um corpo vivo, dinâmico, não pertencendo a grupos sociais, mas, sim, sendo um fenômeno de diferentes realidades sociais.

Também, partindo-se desta perspectiva, possibilita-se aos alunos uma ampliação não só da visão da variedade padrão da língua como também ao emprego de diferentes variedades linguísticas, levando-o a adequar a linguagem verbal às diferentes situações de usos sociais. Além disso, como dito inicialmente neste artigo, se considerarmos que o papel real da educação é formar cidadãos 
e, dentro do sentido de cidadania estão inerentes práticas não preconceituosas, pensar na linguagem como um instrumento social leva o aluno a uma visão não preconceituosa em relação aos diferentes usos da língua que divergem da variedade padrão, uma vez que:

assim como os europeus se consideravam superiores aos negros, aos índios,
aos polinésios, aos aborígines australianos etc., também muitas pessoas das
camadas dominantes da sociedade consideram que os pobres, os analfabetos,
os habitantes da zona rural (e, em alguns lugares, as mulheres, os jovens,
os negros, os imigrantes etc.) não sabem falar, têm vocabulário pobre,
são incapazes de raciocínio lógico. É a expressão mais clara e vigorosa do
preconceito linguístico, conjunto de ideias que se manifestam concretamente
na discriminação da linguagem. (BAGNO, 2014, p. 57).

Acertando as arestas dessa tríade Governo-Escola-Linguística, certamente, o ensino de língua pode, de fato, cumprir seu principal papel: a promoção social do aluno e não sua estratificação. Isso significa considerar suas práticas discursivas, bem como aprender que a língua funciona como uma espécie de "roupeiro", podendo o aluno vestir suas variadas "roupagens", a depender do contexto e situação de uso. Caso contrário, os alunos, sujeitos principais da educação, continuarão sofrendo nesse ambiente preconceituoso, linguisticamente, uma vez que a língua, acima de tudo, funciona como um instrumento de poder, com o qual se aniquila o falante que não consegue dispor de suas muitas variantes.

O minidicionário desenvolvido pelo nono ano, apresentado neste estudo, representa, mesmo que timidamente, uma tentativa de transposição didática dos princípios gerais da Sociolinguística, que demonstra, dentro do escopo da Linguística, a possibilidade de se olhar não somente para a língua, mas, principalmente, para seus usuários (alunos) como sendo um corpo social. Atrelado a isso, a metodologia aqui esboçada, além de fazer refletir os conceitos abordados, o fez em termos pragmáticos, mostrando aos alunos como podem ser percebidos na prática de seus universos linguísticos.

\section{Referências}

ANTUNES, Arnaldo. Beija eu. Letras Mus, [s/d]. Disponível em: https://www.letras. mus.br/arnaldo-antunes/91440/. Acesso em: 02 out. 2019.

BAGNO, M. Língua, linguagem, linguística: pondo os pingos nos ii. São Paulo: Parábola Editorial, 2014.

BAGNO, M. Preconceito Linguístico: o que é, como se faz. São Paulo: Loyola, 2007.

BELINE, R. A variação linguística. In: FIORIN, José Luiz (org). Introdução à

Linguística I. Objetos Teóricos. São Paulo: Contexto, 2015.

CAGLIARI, L. Alfabetização e Linguística. São Paulo: Scipione, 2003. 
CÓSEGAS - Adolescente parte 1. Profdanii. Youtube. 01 jan. 2012. Disponível em: https://www.youtube.com/watch?v=pRjk4jzyBXU. Acesso em: 02 out. 2019.

FORMAÇÃO DE PALAVRAS - ATIVIDADES. Só linguagem. 04 set. 2018.

Disponível em: http://solinguagem.blogspot.com/2018/09/formacao-de-palavrasatividades.html. Acesso em: 02 out. 2019.

LABOV, William. Padrões sociolinguísticos. Trad. Marcos Bagno, Maria Marta Pereira Scherre, Caroline Rodrigues Cardoso. São Paulo: Parábola Editorial, 2008.

NOTA EXPLICATIVA: RESULTADO PROVA BRASIL 2013. In: Portal Inep. Brasil: Inep, s/d. Disponível em <http://download.inep.gov.br/ mailing/2014/nota _explicativa _prova_brasil_2013.pdf>. Acesso em: 18 jun. 2017.

SAUSSURE, F. Curso de Linguística Geral. São Paulo: Cultrix, 2012. 